OPEN ACCESS

Edited by:

Maria De Lourdes Pereira, University of Aveiro, Portugal

Reviewed by: Sonia M. Rodrigues Oliveira, University of Aveiro, Portugal Karma Gurmey Dolma, Sikkim Manipal University, India Ana Cristina Esteves, University of Aveiro, Portugal

*Correspondence: Maha Al-Asmakh maha.alasmakh@qu.edu.qa

Specialty section:

This article was submitted to Microbiome in Health and Disease,

a section of the journal

Frontiers in Cellular and Infection Microbiology

Received: 29 November 2021 Accepted: 26 January 2022 Published: 21 February 2022

Citation:

Zakaria ZZ, Al-Rumaihi S, Al-Absi RS, Farah H, Elamin M, Nader R, Bouabidi S, Suleiman SE, Nasr S and Al-Asmakh M (2022)

Physiological Changes and Interactions Between Microbiome and the Host During Pregnancy. Front. Cell. Infect. Microbiol. 12:824925. doi: 10.3389/fcimb.2022.824925

\section{Physiological Changes and Interactions Between Microbiome and the Host During Pregnancy}

\author{
Zain Zaki Zakaria ${ }^{1,2}$, Shouq Al-Rumaihi ${ }^{1}$, Rana S. Al-Absi ${ }^{3}$, Huda Farah ${ }^{1}$, Muram Elamin ${ }^{1}$, \\ Rahaf Nader ${ }^{1}$, Salma Bouabidi ${ }^{1}$, Sara Elgaili Suleiman ${ }^{1}$, Shahd Nasr $^{1}$ and Maha Al-Asmakh ${ }^{1,2^{\star}}$ \\ 1 Department of Biomedical Sciences, College of Health Sciences, Qatar University (QU) Health, Qatar University, Doha, \\ Qatar, 2 Biomedical Research Center, Qatar University (QU), Doha, Qatar, ${ }^{3}$ Department of Biological and Environmental \\ Sciences, College of Arts and Sciences, Qatar University (QU), Doha, Qatar
}

In recent years, it has become clear that microbiome play a variety of essential roles in human metabolism, immunity, and overall health and that the composition of these microbiome is influenced by our environment, diet, weight, hormones, and other factors. Indeed, numerous physiological and pathological conditions, including obesity and metabolic syndrome, are associated with changes in our microbiome, referred to as dysbiosis. As a result, it is not surprising that such changes occur during pregnancy, which includes substantial weight gain and significant changes in metabolism and immune defenses. The present review relates physiological changes during pregnancy to alterations in the microbial composition at various sites, including the gut, oral cavity, and vagina. Pregnancy has been linked to such microbial changes, and we believe that, in contrast to certain disease states, these microbial changes are vital for a healthy pregnancy, probably through their influence on the mother's immunological, endocrinological, and metabolic status.

Keywords: microbiome, pregnancy, oral microbiota, gut microbiota, vaginal microbiota, probiotics, physiological changes

\section{INTRODUCTION}

To ensure a healthy environment for fetal development, pregnancy is associated with pronounced changes in metabolism, hormonal status and immunological defenses, all of which may be influenced by microbiota resident in the gut, vagina, placenta and oral cavity (Nuriel-Ohayon et al., 2016). For example, changes in the endocrine system in response to maternal factors such as diet and usage of antibiotics influence the compositions of the gut and oral microbiome (NurielOhayon et al., 2019, Amir et al., 2020). Moreover, progesterone can increase the abundance of bifidobacterium in the gut (Nuriel-Ohayon et al., 2019; Amir et al., 2020).

Dysbiosis of the gut microbiome during pregnancy is associated with gestational diabetes, preeclampsia and restricted fetal growth. In addition, certain oral bacteria are pathogenic and can exert deleterious effects on the health and maturation of the fetus. Periodontal infections that are transmitted to other locations can lead to premature birth, low birth weight, and preeclampsia (Figuero et al., 2020) so that virtually all pregnant women require periodontal care (Rapone et al., 2020). 
Here, we summarize recent research findings regarding alterations in microbiome during pregnancy.

\section{PHYSIOLOGICAL CHANGES DURING PREGNANCY}

To support the healthy growth and development of the fetus, pregnant women undergo changes in their endocrine, cardiovascular, respiratory, renal, and digestive systems.

\section{Changes in the Endocrine System}

Already upon conception, the levels of certain hormones in a woman increase. Upon successful implantation of a fertilized egg into the uterine wall, placental trophoblasts begin to produce human chronic gonadotrophin (hCG) (Miller et al., 2020), the level of which rises during the first few weeks of pregnancy until it reaches its peak level of approximately $20000 \mathrm{mIU} / \mathrm{mL}$ during weeks 10-12, and thereafter, and at the end of the first trimester, falls steadily (Hendriks et al., 2019). hCG stimulates cells in the corpus luteum to start producing progesterone and estrogen, the levels of which increase as pregnancy progresses and the placenta grows, reaching their peaks during the third trimester (Sykes and Bennett, 2018). In addition, the hCG hormone is involved in the formation of vessels and the placenta, the differentiation of fetal cells and growth of fetal organs and preventing premature contractions of the uterus musculature (Barjaktarovic et al., 2017).

The many processes mediated by progesterone include the adaptation of the cervix for implantation of the fetus and differentiation of stromal cells into decidual cells. Furthermore, increasing progesterone levels prevent uterine contractions both by diminishing the levels of receptors for prostaglandin and oxytocin and directly inhibiting the contraction of resident smooth muscle cells (Sykes and Bennett, 2018). Rising estrogen levels are responsible for neoangiogenesis and the formation of tissues that become the placenta and support lactation (NoyolaMartínez et al., 2019). These hormonal changes cause the typical fatigue, nausea, constipation, and headaches associated with early pregnancy (Fuhler, 2020). Moreover, the growing placenta also produces hormones, including human placental lactogen (HPL), relaxin and human chronic gonadotrophin.

In addition, the thyroid gland of pregnant women may become more active, leading to hyperthyroidism (Kobaly and Mandel, 2019). Placental hormones such as lactogen promote insulin resistance, which is often accompanied by elevated production of insulin. Therefore, to avoid excessive plasma concentrations of glucose, pregnant women are often advised to pay attention to regulating their intake of carbohydrates (Mockridge and Maclennan, 2019)

\section{Circulatory and Cardiovascular Changes}

A major cause of the cardiovascular changes associated with pregnancy is relaxation of the vascular smooth muscle in response to the increased circulating levels of estrogens, progesterone, and prostaglandins (Morton, 2021). Moreover, these hormonal changes lower the resistance of the pulmonary and systemic vessels and, thereby, blood pressure, which in most cases eventually returns to the non-pregnant value by the third trimester. Furthermore, the diastolic and stroke volumes and heart rate are elevated during pregnancy (Chen and Basso, 2007), resulting in a continuous increase in cardiac output, especially during the second and third trimesters (Morton, 2020). This increase, which can be as much as 50\% during the third trimester, is targeted primarily to the placenta and uterus to nourish the growing fetus and the breasts in preparation for breastfeeding the newborn infant (Elkus and Popovich, 1992).

Furthermore, during the early phase of pregnancy, activation of the renin-angiotensin-aldosterone system causes sodium and water retention. Ultimately, this could expand the plasma volume and dilute the number of red blood cells (Claros et al., 2020), leading to anemia. In this context, the requirement for iron increases two- to three-fold, and many women experience iron deficiency during the second trimester of their pregnancy (Scholl and Reilly, 2000). The fetus requires this additional iron to synthesize hemoglobin and certain other enzymatic functions. In addition, capillary wedge and oncotic pressure reductions make pregnant women susceptible to pulmonary edema (Jarvis and Nelson-Piercy, 2020).

\section{Respiratory Changes}

To fulfill the requirement of the developing fetus for oxygen, the respiratory system undergoes several physiological and anatomical changes, including elevated tidal volume, ventilation, and respiratory rate (Lemos et al., 2010; Hegewald and Crapo, 2011). At the same time, the expiratory reserve volume, total pulmonary capacity, and functional residual capacity all decline during gestation (Lemos et al., 2010), mainly due to alterations in the flexibility of ligaments in response to the higher levels of progesterone. In addition, the rise in intra-abdominal pressure as the uterus grows contributes considerably to these respiratory effects (Lee et al., 2017).

Moreover, this increase in ventilation causes the partial pressures of oxygen $\left(\mathrm{paO}_{2}\right)$ and carbon dioxide $\left(\mathrm{paO}_{2}\right)$ to be augmented and attenuated, respectively. These changes should, in turn, facilitate gas exchange across the placenta.

\section{Changes in the Renal System}

During pregnancy, the renal system undergoes several physiological and anatomical adaptations designed to support the development of the fetus. One major change of this sort is enlargement and increased weight of the kidneys due to a larger interstitial volume and more extensive vasculature (Cheung and Lafayette, 2013). Moreover, due to the tremendous pressure exerted by the growing fetus (Cheung and Lafayette, 2013), the capacity of the mother's bladder decreases, causing more frequent urination, one of the most common symptoms associated with pregnancy. In addition, renal blood flow may be elevated, increasing the glomerular filtration rate by as much as $50 \%$ and thereby reducing serum levels of creatinine (Park et al., 2017). Finally, both relaxation of smooth muscles in response to elevated progesterone levels and mechanical 
compression by the enlarging uterus can lead to retention of urine and hydronephrosis (Suarez et al., 2019).

As a result of the changes in the renal system during pregnancy this can also lead to deficiencies and raised levels of certain solutes. One change is hyponatremia which is caused by the high levels of hCG in pregnancy (Abbassi-Ghanavati et al., 2009). Another change is proteinuria due to protein excretion in urine being higher than normal. This is believed to be a result of multiple factors such as the increased Glomerular filtration rate (GFR), increased protein transport across the glomerular barrier as well as the decreased reabsorption offiltered protein (Kattah et al., 2017). Glucosuria is also another possible outcome, seen in around $50 \%$ of pregnant patients. It is mainly caused by decreased absorption of glucose in the proximal tubule (Alto, 2005).

\section{Changes in the Gastrointestinal System}

Nausea, vomiting, heartburn, and constipation, the most common symptoms associated with pregnancy, are caused by changes in the gastrointestinal tract as the uterus enlarges (Herrero et al., 2001; Body and Christie, 2016). In addition, rising progesterone levels relax the lower esophageal sphincter, promoting reflux into the gastro-esophagus and, ultimately, heartburn (Jarvis and Nelson-Piercy, 2020). At the same time, pregnancy leads to constipation by slowing down gastric emptying. Furthermore, pregnant women are more prone to develop gallstones due to their elevated progesterone levels, which relaxes muscles, inhibits the release of cholecystokinin, and may thereby result in biliary stasis (Mockridge and Maclennan, 2019).

\section{Changes in the Hematologic System}

As with every other system in the body, the hematologic system also experiences changes during pregnancy. The most significant changes include expanded plasma volume accompanied with a higher red blood cell mass that leads to physiologic anemia as mentioned earlier (Bernstein et al., 2001). Additionally, during the first trimester white blood cells increase due to the physiological stress that pregnancy places on the body. This is especially evident with neutrophils. The most likely reason for this is the lack of neutrophilic apoptosis ability during pregnancy as a result of an increase in inhibitory factors in the serum. In addition, there is an increase in the number of myelocytes and metamyelocytes which indicate the increased level of activity in the bone marrow and erythropoiesis during pregnancy. In the first and second trimesters there is also a decrease in the lymphocyte count, compared to an increase in the third trimester (Chandra et al., 2012; Al-Shafei et al., 2020). Studies have also shown that platelet counts decrease in pregnancy, mainly in the third trimester. This is known as gestational thrombocytopenia, which occurs as a result of the hemodilution present in pregnancy accompanied with increased platelet activation and clearance. Pregnancy is also associated with an increase in the levels of coagulation factors due to the increase in estrogen levels during this time, resulting in a prothrombotic state, especially in the third trimester (Patel and Balanchivadze, 2021). Table 1 and Figure 1 summarize the physiological changes associated with pregnancy.

\section{CHANGES IN MICROBIOME ASSOCIATED WITH PREGNANCY}

\section{The Gut Microbiome}

The gastrointestinal tract is colonized by various microorganisms, including bacteria, protozoa, viruses and archaean and the composition of this microbiome varies with age. In adult humans, approximately $80 \%$ of this microbiome consists of bacteria belonging to the phyla Actinobacteria, Firmicutes and Bacteroidetes (Baldassarre et al., 2018). In the case of the neonate, colonization of the gut, which occurs during and after birth, is affected by mode of delivery and breastfeeding. The neonatal gut is colonized immediately for the most part by Enterococci, Staphylococci, and Enterobacteria; during the first days of post-natal life, Lactobacillus, Clostridium, Bifidobacterium, and Bacteroides take up residence; and the gut composition of bacteria become similar to that of adults at one year of age (Baldassarre et al., 2018).

Most pregnancies progress without incident. But approximately 8 percent of all pregnancies involves deleterious fetal and maternal health complications, the most common being preterm birth, diminished intrauterine growth, preeclampsia, and eclampsia (Maresh, 1990). The gut microbiota associated with normal and complicated pregnancies differ and the physiological changes, including the rise in the progesterone level, affect the composition of the maternal microbiome. More specifically, the microbiome in pregnant women contains a larger proportion of, in particular, Bifidobacterium, but also of Proteobacteria and Actinobacteria (Koren et al., 2012). During the third trimester alpha diversity is reduced, while both beta diversity and the abundance of opportunistic pathogens are elevated.

Some researchers have concluded that these changes are temporary and of no significance (DiGiulio et al., 2015; Yang et al., 2020), whereas others have found that insertion of human gut microbes from the third trimester into mice leads to weight gain and more pronounced low-grade inflammation (Turjeman et al., 2021). Furthermore, all alterations in the gut microbiome directly influence maternal metabolism (Paul et al., 2018), which, in turn, impacts the development and growth of fetal organs (Jiang et al., 2021).

In addition, the composition of the gut microbiome may be altered by poor dental health or inflammatory bowel disease in a manner linked to an increased risk for spontaneous premature delivery. In one investigation, the beta diversity of the maternal gut microbiota was found to differ between those who delivered preterm and normal deliveries (Hiltunen et al., 2021). In another case, mothers who underwent spontaneous preterm delivery exhibited lower diversity in their gut microbiome, particularly with respect to Bifidobacterium and Streptococcus (Dahl et al., 2017).

Moreover, gut microbes can give rise to intrauterine infection, as reflected in the presence of these microbes in the amniotic 
TABLE 1 | Physiological changes during pregnancy.

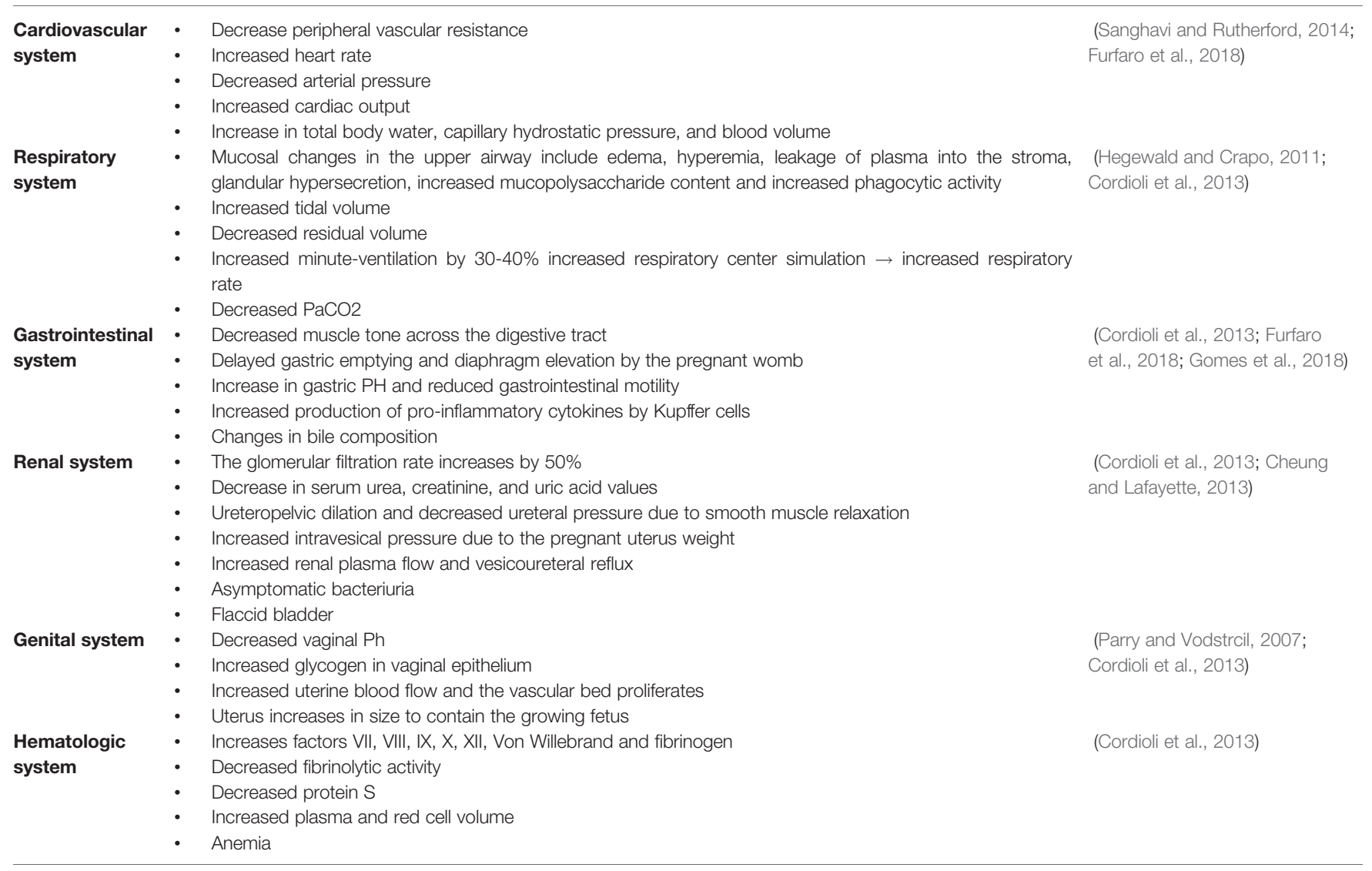

Endocrine system changes

Production of hCG stimulates cells in the corpus luteum to begin synthesizing progesterone and estrogen.

\section{Respiratory changes}

To supply the oxygen required by the developing fetus, the tidal volume, ventilation and respiratory rate are all enhanced.

\section{Gastrointestinal system changes}

Progesterone relaxes the lower esophagael sphincter, resulting in reflux into the gastro-esphagus and, ultimately, heartburn.

\section{Circulatory \& cardiovascular changes}

Increases in the circulating levels of estrogens, progesterone and prostaglandins relax vascular smooth muscle

\section{Renal system changes}

The kidneys become larger and increase in weight, while the capacity of the mother's bladder is diminished, leading to more frequent urination.

\section{Hematologic systemchanges}

Plasma volume expand accompanied by increase in RBC mass, WBC number, level of coagulation factor and a decrease in platelet counts.

FIGURE 1 | Physiological changes associated with pregnancy.

fluid of women who experienced premature rupture of membranes (Edwards et al., 2017). The mechanism by which gut microbes move to the uterus is not yet known, but two possible mechanisms have been proposed: the first is that gramnegative bacteria, which express lipopolysaccharide that elicits the production of prostaglandins and other mediators of inflammation, ascend via the vagina; and the second, that the content of the gut leaks into the uterus or placenta (Edwards et al., 2017).

\section{The Oral Microbiome}

The healthy human oral cavity contains approximately 50-100 million bacteria belonging to 700 species (Kilian et al., 2016), 
including Lactobacilli, Staphylococci, Streptococcus (Dewhirst et al., 2010; Kumar et al., 2013; Saadaoui et al., 2021). The composition of this complex community is affected by several factors, such as nutrition, oxygen levels, and $\mathrm{pH}$ (Saadaoui et al., 2021). Imbalances in the oral microbiome have been found to be associated with certain diseases, as well as with pregnancy. Imbalances in the oral microbiota, particularly during pregnancy, have been linked to a variety of disorders (Farrell et al., 2012). In fact, the oral microbiome of a healthy pregnant woman and a pregnant woman with certain diseases, e.g., gestational diabetes, differ (Li et al., 2021).

The changes in microbiome that occur in connection with pregnancy include the microbiome in the oral cavity (Saadaoui et al., 2021; Turjeman et al., 2021). For instance, the microbiome detected in saliva differs between pregnant and non-pregnant women, with the former showing an abundance of, e.g., Porphyromonas, Treponema and Neisseria, while in the latter, Veillonella and Streptococcus were overrepresented (Lin et al., 2018). The oral microbiome of pregnant women contain high numbers of bacteria, mainly during the first trimester (Fujiwara et al., 2017) including Porphyromonas, Neisseria, and Treponema (Lin et al., 2018) and certain pathogenic bacteria (Chong et al., 2018). Moreover, certain specific species of bacteria, such as Staphylococci, Streptococci, Aggregatibacter actinomycetemcomitans, and Porphyromonas gingivalis, are more abundant in the oral microbiome during the first and second trimesters of pregnancy. During pregnancy, the proliferation and growth of Streptococcus, Lactobacillus, Escherichia coli, and Bifidobacterium species vary (Pelzer et al., 2012).

Furthermore, the hormonal changes that pregnant women undergo promote the formation of bacterial plaque, thereby resulting in gingivitis, especially during the second to third trimesters (de Souza Massoni et al., 2019), which causes complications of pregnancy such as preeclampsia, preterm birth (PTB), low birth weight, and miscarriage (Cobb et al., 2017). The amniotic fluid of a woman who went into preterm labor contained Fusobacterium nucleatum, suggesting that oral bacteria can translocate to the placenta (Nuriel-Ohayon et al., 2019; Amir et al., 2020). In another woman who suffered from gingivitis and gave an unusual full-term stillbirth, Fusobacterium nucleatum was detected in both the placenta and newborn infant, indicating that this bacterium originated from the maternal subgingival plaque (Nuriel-Ohayon et al., 2019; Amir et al., 2020). It appears possible that the environments in the oral cavity and placenta contain similar factors that promote colonization and growth of Fusobacterium nucleatum (Nuriel-Ohayon et al., 2019; Amir et al., 2020).

In addition, a positive correlation between the presence of a periodontopathogen (Porphyromonas gingivalis) and progesterone levels in the first trimester of pregnancy was observed (de Souza Massoni et al., 2019). Other studies confirmed the growth of certain gram-negative anaerobic bacteria, including Prevotella nigrescens, Campylobacter rectus (Yokoyama et al., 2008; Gürsoy et al., 2009), and Prevotella intermedia (Muramatsu and Takaesu, 1994), which is promoted by the hormonal changes that occur during pregnancy. Moreover, high estrogen levels promote infection by Candida (Kumar et al., 2013; Fujiwara et al., 2017).
Willmott and co-workers (2020) demonstrated that the composition of the oral microbiome accurately reflects the dietary content of nitrate and the healthy regulation of blood pressure (Willmott et al., 2020). Bacteria in the oral cavity, located primarily on the tongue's surface, reduce nitrate enzymatically, resulting in the presence of nitrite in the saliva, which is subsequently transformed in the stomach into nitric acid and then reduced to nitric oxide (NO). This process is related to blood pressure in two different ways: the plasma level of nitrate is related inversely to blood pressure, and, at the same time, $\mathrm{NO}$ is a key signal molecule in connection with processes that regulate the circulatory system (Willmott et al., 2020).

Nitric Oxide (NO) is one of the reaction products produced by nitric oxide synthase (NOS) enzymes that catalyze NADPH and tetrahydrobiopterin (BH4)-dependent oxidation of $\mathrm{L}$ arginine to L-citrulline (Ghimire et al., 2017). Nitric oxide serves in a wide aspect of human physiology and it takes part in vasodilation, endothelial function, mitochondrial function, prevention of platelets aggregation, neurotransmission, immune defense, and metabolism (Hezel and Weitzberg, 2015). In research from Walker et al., (2018) it was indicated that The oral microbiome play an important role in the production of the nitric oxide (NO) through nitrate-nitrite-NO pathway. The oral microbiota is deficient in the NO enzymes responsible for yielding the catalyzed NO from L-arginine (Qu et al., 2016; Willmott et al., 2020). According to Walker et al., (2018), the production of nitric oxide occurs in the human body by two methods: dependent and independent. Furthermore, the microbiome in the human body produces $\mathrm{NO}$ in an independent way through fermentation depending on food intake by the consumption of nitrate $\left(\mathrm{NO}^{-}\right)$and nitrite $(\mathrm{NO} 2$ ). In addition, oral microbiota has a major role in cardiovascular system wellbeing and in the regulation of blood pressure, including in pregnancy (Willmott et al., 2020). A case-control study in a tertiary facility in Ghana (Darkwa et al., 2018) found that the level of serum nitric oxide rises rapidly during pregnancy and peaks during the third trimester of a healthy pregnancy. However, other research found that the progressive rise in serum nitric oxide levels during pregnancy is not significant. According to (Zullino et al., 2018), nitric oxide is the principal vasodilator in the placenta, making it crucial to several physiological functions of an uncomplicated pregnancy. Placental perfusion, platelet adhesion and aggregation in the intervillous space, and fetoplacental vascular response are all regulated by NO during implantation, early embryonic development, and feto-placental vascular reaction (Zullino et al., 2018).

\section{The Vaginal Microbiome}

The composition of the vaginal microbiome, which plays an essential role in both maternal and fetal health (Nelson et al., 2016), can be altered by many different factors, including hormones, sexual practices, pregnancy, hygiene, urogenital infections and pharmacological treatments (Kroon et al., 2018; Noyes et al., 2018; Parolin et al., 2018). Typically, Lactobacilli predominate and, together with other bacterial species, maintain a $\mathrm{pH}$ of 3.8-4.5 
(Mendling, 2016). The vaginal environment changes dramatically during pregnancy, resulting in an even greater abundance of Lactobacillus spp. and pronounced changes in the metabolic profiles of the bacteria present (Marangoni et al., 2021). Complicated pregnancies and preterm birth are associated with less Lactobacilli and a greater variety of bacteria (Di Simone et al., 2020).

Several investigations into a potential link between the composition of the vaginal microbiome and miscarriage have revealed that miscarriages during the first trimester appear to associate with lower levels of Lactobacillus spp. and more pronounced alpha diversity. The presence of pathogenic microorganisms raises the risk for infections such as bacterial vaginosis, which has been linked to premature rupture of membranes and preterm birth. A meta-analysis concluded that, even after controlling for other major risk factors, the risk of preterm delivery in women with bacterial vaginosis caused by, e.g., Prevotella bivia, Peptostreptococcus, and/or G. vaginalis increased more than two-fold (Leitich et al., 2003). Moreover, a higher risk for preterm birth rate was correlated with the presence of specific vaginal fungi such as Candida albicans (Neuman and Koren, 2017) and variations in the vaginal $\mathrm{pH}$ caused by changes in the microbiome (Mysorekar and Cao, 2014).
In addition to the factors mentioned above, the composition of the vaginal microbiota is influenced by ethnic background and genetic polymorphisms that affect the ability to produce anti- or promicrobial substances. Such polymorphisms are present in the genes that encode the antagonist of the interleukin 1 (IL-1) receptor and the Toll-like receptor (TLR) 4, which acts in the innate recognition of Gram-negative bacteria and can influence individual susceptibility to complications during pregnancy (Mendling, 2016). Furthermore, women who have embryonic miscarriages exhibit higher vaginal levels of interleukin 2 (IL-2) and lower levels of interleukin 10 (IL-10) than control subjects (Xu et al., 2020). Table 2 summarize the change in the maternal microbiome during pregnancy. And Figure 2 shows the potential mechanisms of crosstalk between maternal microbiota and offspring immunity.

\section{THE EFFECT OF PROBIOTICS ON MICROBIOME DURING PREGNANCY}

The World Health Organization (WHO) defines probiotics as live microorganisms that, upon administration through the diet or as a

TABLE 2 | List of organisms and their associated effects during pregnancy.

\begin{tabular}{|c|c|c|}
\hline Causative microbiome & Effects on pregnancy & Reference \\
\hline \multicolumn{3}{|l|}{ The gut microbiome } \\
\hline Bifidobacteria & Atopic eczema and asthma & (Baldassarre et al., 2018) \\
\hline Enterobacteriaceae & Preterm newborns & (Baldassarre et al., 2018) \\
\hline \multicolumn{3}{|l|}{ Enterococcaceae } \\
\hline Proteobacteria & Metabolic syndrome such as weight gain, hyperglycemia, & (Koren et al., 2012) \\
\hline Actinobacteria & insulin resistance. & \\
\hline Prevotella & Protection against food allergies and Gestational diabetes & (Koren et al., 2012; Turjeman et al., 2021) \\
\hline $\begin{array}{l}\text { Staphylococcus spp, } \\
\text { Escherichia coli }\end{array}$ & Weight gain & (Turjeman et al., 2021) \\
\hline \multicolumn{3}{|l|}{$\begin{array}{l}\text { Enterobacteriaceae, DesulfovibrioParabacteroides } \\
\text { distasonis }\end{array}$} \\
\hline \multicolumn{3}{|l|}{$\begin{array}{l}\text { Clostridium perfringens, } \\
\text { Fusobacterium and Veillonella }\end{array}$} \\
\hline $\begin{array}{l}\text { Planococcaceae, Lactobacillaceae and } \\
\text { Enterobacteriaceae }\end{array}$ & Preterm neonates & (Hiltunen et al., 2021) \\
\hline Bifidobacterium & Preterm neonates & (Dahl et al., 2018) \\
\hline \multicolumn{3}{|l|}{ Streptococcus } \\
\hline Listeria monocytogenes & Still birth & (Edwards et al., 2017) \\
\hline \multicolumn{3}{|l|}{ The oral microbiome } \\
\hline Pg and intrauterine Bergeyella & Delivered prematurely & (Saadaoui et al., 2021) \\
\hline Lautropia and Neisseria & Saliva and dental plaque & (Li et al., 2021) \\
\hline Porphyromonas gingivalis & $\begin{array}{l}\text { Periodontal inflammation, placentas of patients with } \\
\text { preeclampsia }\end{array}$ & (Cobb et al., 2017; Lin et al., 2018) \\
\hline Filifactor alocis & Placentas of patients with preeclampsia & (Cobb et al., 2017) \\
\hline Fusobacterium nucleatum & $\begin{array}{l}\text { Preterm birth, periodontal disease and adverse pregnancy } \\
\text { complications }\end{array}$ & $\begin{array}{l}\text { (Cobb et al., 2017; Amir et al., 2020; Saadaoui } \\
\text { et al., 2021) }\end{array}$ \\
\hline Prevotella nigrescens & Pregnancy gingivitis & (Gürsoy et al., 2009) \\
\hline Genera Rothia and Staphylococcus & Oral nitrate reduction & (Willmott et al., 2020) \\
\hline Prevotella & Oral nitrate reduction & (Willmott et al., 2020) \\
\hline \multicolumn{3}{|l|}{ The vaginal microbiome } \\
\hline Lactobacilli & Pregnancy-related complications and preterm birth & (Di Simone et al., 2020) \\
\hline $\begin{array}{l}\text { Prevotella bivia, Peptostreptococcus, and/or G. } \\
\text { vaginalis }\end{array}$ & Preterm delivery & (Leitich et al., 2003) \\
\hline Candida albicans & Preterm delivery & (Neuman and Koren, 2017) \\
\hline
\end{tabular}




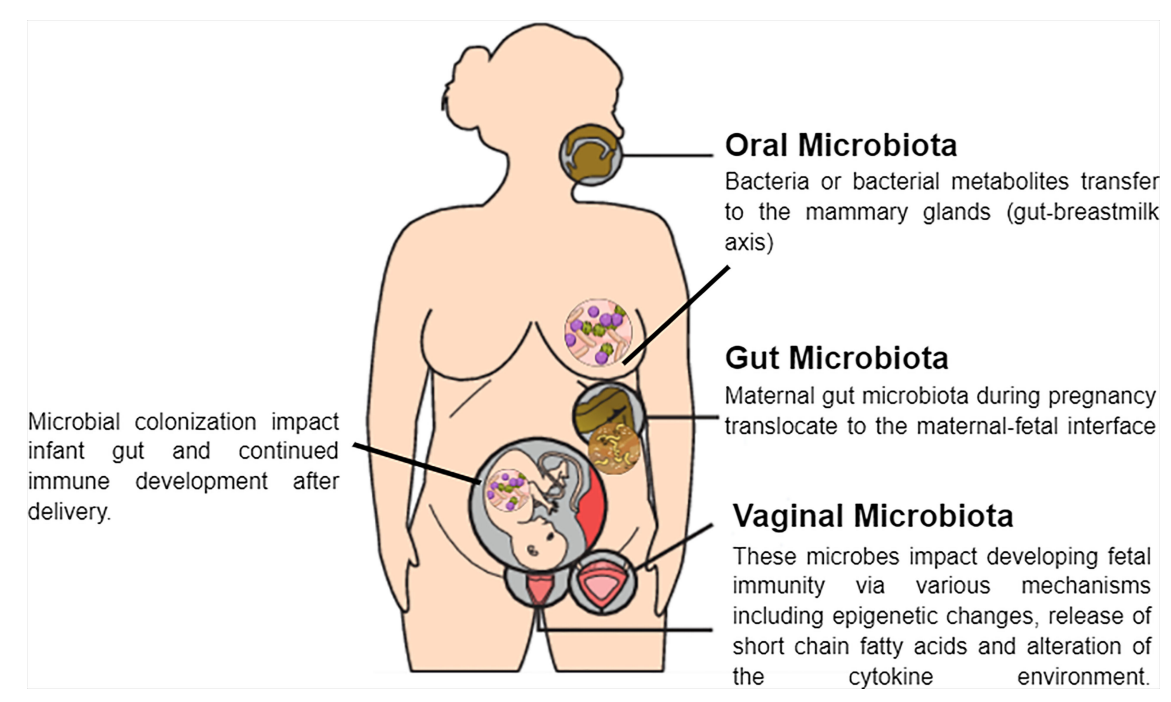

FIGURE 2 | Potential mechanisms of crosstalk between maternal microbiota and the fetus.

supplement, have beneficial effects on the host (Buggio et al., 2019). A variety of studies indicate that by regulating the gut and vaginal microflora, the right combination of probiotics (Baldassarre et al., 2018) can lessen the risk of pregnancy complications such as preterm birth (Arango et al., 2015). It was proposed recently that probiotics prevent preterm birth by altering the composition and function of the gut microbiome to improve maternal glucose metabolism (Buggio et al., 2019).

However, findings in this area are controversial. For instance, one study that included 4098 women found that probiotics can either decrease or increase the risk for birth between weeks 34-37 of pregnancy (Buggio et al., 2019), supporting the proposal that more detailed investigations on the types of probiotic, the characteristics of individual women and length of administration are required (Jarde et al., 2018). In another case, probiotics provided no protection and were shown to be capable of initiating the inflammatory cascade associated with preterm birth (Othman et al., 2007; Arango et al., 2015). In contrast, dietary supplementation with probiotics has been reported to reduce the abundance of Bifidobacterium and attenuate the increase in Atopobium vaginae that is linked with more than $70 \%$ of cases of bacterial vaginosis, which causes preterm birth (Baldassarre et al., 2019). At the same time, it appears that following antibiotic treatment, supplementary probiotics can lower the vaginal $\mathrm{pH}$ to an optimal value hence promoting the restoration of vaginal microbiota, thereby preventing the reduction in levels of antiinflammatory cytokines (Baldassarre et al., 2019).

Moreover, the administration of probiotics during pregnancy has been shown to raise the levels of anti-inflammatory molecules such as IL-10 and TGF-B in breast milk, which aids in the maturation of the infant's gut by stimulating the secretion of IgA and oral tolerance (Baldassarre et al., 2018). Furthermore, probiotics can effectively prevent allergic reactions. The lymphoid system of the newborn is not fully developed, with a limited Th1 response, and the microbiota plays an essential role in bridging this gap between Th1 and Th2 responses. Accordingly, alteration of the gut microbiota that results in loss of this modulation of inflammatory cytokines can augment the risk for development of atopic eczema (Baldassarre et al., 2018).

More than $15 \%$ of young infants suffer from gestational disorders such as infantile colic. Probiotics can influence the pathogenesis of such disorders by altering the composition of the gut microbiome, which is involved in direct bidirectional relationships with the brain. The three mechanisms proposed as explanations for this influence by probiotics include alterations in the secretion of cytokines and chemokines, involvement of microbiota in neural pathways, and stimulation of the intestinal neuroendocrine pathway. Interestingly, the usage of a mixture of probiotics has been found to reduce crying by infants with colic during breastfeeding (Baldassarre et al., 2018), and probiotics appear to significantly impact the composition of the neonatal microbiota. It has been suggested that probiotics such as Lactobacillus can interact directly with the host via pattern recognition receptors (PRR), for which the peptidoglycan in the wall of gram-positive bacteria and lipopolysaccharide of gramnegative bacteria serve as ligands (Devi et al., 2021). The direct interaction involves the binding of probiotic bacteria to these receptors on the host's dendritic and intestinal epithelial cells, thereby preventing cytokine-induced apoptosis and production of defensins and mucus (Devi et al., 2021).

Another proposed mechanism involves the generation of toxic or antimicrobial compounds such as bacteriocin by probiotics (Oktaviyani et al., 2021). For example, Lactobacillus crispatus F177 and Lactobacillus paracasei F2 and F28 produce hydrogen peroxide, which suppresses the growth of Staphylococcus aureus. In addition, probiotics compete with pathogenic species for adhesion to the surface of intestinal epithelial cells. Adhesion molecules such as a mucus-binding protein on the surface of probiotics facilitate 
their interaction with host dendritic cells, thus enhancing the phagocytic capacity of these cells (Devi et al., 2021).

\section{CONCLUSIONS}

In this review, we describe the changes in the compositions of the gut, oral and vaginal microbiome that occur in connection with pregnancy. The hormonal, immunological and metabolic changes that pregnant women undergo influence these compositions and vice-versa, appropriate adaptation is required to support optimal fetal growth and development.

Imbalances in the microbiota can lead to complications of pregnancy such gestational diabetes, preterm delivery and preeclampsia. Manipulating microbiome composition during pregnancy through probiotics could result in improved maternal health and pregnancy outcomes. Maternal micorbioem and fetal interaction during pregancy is critical for fetal developemt.

\section{REFERENCES}

Abbassi-Ghanavati, M., Greer, L. G., and Cunningham, F. G. (2009). Pregnancy and Laboratory Studies: A Reference Table for Clinicians. Obstet. Gynecol. 114 (6), 1326-1331. doi: 10.1097/AOG.0b013e3181c2bde8

Al-Shafei, A. I., Musa, S. M., Rayis, D. A., Lutfi, M. F., El-Gendy, O. A., and Adam, I.. (2020). Heart Rate Variability and Hematological Parameters in Pregnant Women. J. Clin. Lab. Anal. 34 (6), e23250. doi: 10.1002/jcla.23250

Alto, W. A. (2005). No Need for Glycosuria/Proteinuria Screen in Pregnant Women. J. Fam. Pract. 54 (11), 978-983.

Amir, M., Brown, J. A., Rager, S. L., Sanidad, K. Z., Ananthanarayanan, A., and Zeng, M. Y.. (2020). Maternal Microbiome and Infections in Pregnancy. Microorganisms 8 (12), 1996. doi: 10.3390/microorganisms8121996

Arango, L. F. G., Barrett, H. L., Callaway, L. K., and Nitert, M. D.. (2015). Probiotics and Pregnancy. Curr. Diabetes Rep. 15 (1), 567. doi: 10.1007/s11892014-0567-0

Staying-Healthy-During-Pregnancy: 4 Common Pregnancy Complications. Available at: www.hopkinsmedicine.orghttps://www.hopkinsmedicine.org/health/ conditions-and-diseases/staying-healthy-during-pregnancy/4-commonpregnancy-complications.

Baldassarre, M. E., Di Mauro, A., Capozza, M., Rizzo, V., Schettini, F., Panza, R., et al. (2018). Rationale of Probiotic Supplementation During Pregnancy and Neonatal Period. Nutrients 10 (11), 1693. doi: 10.3390/nu10111693

Baldassarre, M. E., Palladino, V., Amoruso, A., Pindinelli, S., Mastromarino, P., Fanelli, M., et al. (2019). Dysbiosis and Prematurity: Is There a Role for Probiotics? Nutrients 11 (6), 1273. doi: 10.3390/nu11061273

Barjaktarovic, M., Korevaar, T. I., Jaddoe, V. W., de Rijke, Y. B., Visser, T. J., Peeters, R. P., et al. (2017). Human Chorionic Gonadotropin (hCG) Concentrations During the Late First Trimester Are Associated With Fetal Growth in a Fetal Sex-Specific Manner. Eur. J. Epidemiol. 32 (2), 135-144. doi: 10.1007/s10654-016-0201-3

Bernstein, I. M., Ziegler, W., and Badger, G. J. (2001). Plasma Volume Expansion in Early Pregnancy. Obstet. Gynecol. 97 (5 Pt 1), 669-672. doi: 10.1016/s00297844(00)01222-9

Body, C., and Christie, J. A. (2016). Gastrointestinal Diseases in Pregnancy: Nausea, Vomiting, Hyperemesis Gravidarum, Gastroesophageal Reflux Disease, Constipation, and Diarrhea. Gastroenterol. Clin 45 (2), 267-283. doi: 10.1016/j.gtc.2016.02.005

Buggio, L., Somigliana, E., Borghi, A., and Vercellini, P. (2019). Probiotics and Vaginal Microecology: Fact or Fancy? BMC Women's Health 19 (1), 1-6. doi: 10.1186/s12905-019-0723-4

Chandra, S., Tripathi, A. K., Mishra, S., Amzarul, M., and Vaish, A. K. (2012). Physiological Changes in Hematological Parameters During Pregnancy.
The mechanisms by which these microbiome and the host interact during pregnancy and regulation of these interactions require elucidation.

\section{AUTHOR CONTRIBUTIONS}

Conceptualization, ZZ \& MA-A; writing-original draft preparation, SA-R, RA, HF, ME, RN, SB, SS, and SN; Figure design and tables, ZZ; writing - review and editing ZZ \& MA-A; funding acquisition, MA-A. All authors contributed to the article and approved the submitted version.

\section{FUNDING}

This research was funded by Qatar National Research Fund (QNRF), grant number UREP26-104-3-044.

Indian J. Hematol. Blood Transfus. 28 (3), 144-146. doi: 10.1007/s12288012-0175-6

Chen, A., and Basso, O. (2007). Does Low Maternal Blood Pressure During Pregnancy Increase the Risk of Perinatal Death? Epidemiol. (Cambridge. Mass.) 18 (5), 619. doi: 10.1097/ede.0b013e31812713e6

Cheung, K. L., and Lafayette, R. A. (2013). Renal Physiology of Pregnancy. Adv. Chronic. Kidney Dis. 20 (3), 209-214. doi: 10.1053/j.ackd.2013.01.012

Chong, C. Y. L., Bloomfield, F. H., and O’Sullivan, J. M. (2018). Factors Affecting Gastrointestinal Microbiome Development in Neonates. Nutrients 10 (3), 274. doi: $10.3390 /$ nu10030274

Claros, N. M., de la Fuente, J. A., Cardiel, M. A., Donaire, J. G., and Herráiz, M. (2020). Papel Del Sistema Renina-Angiotensina En El Embarazo Y La Preeclampsia. Hipertensión. y. Riesgo. Vasc. 37 (2), 72-77. doi: 10.1016/ j.hipert.2020.02.003

Cobb, C. M., Kelly, P. J., Williams, K. B., Babbar, S., Angolkar, M., and Derman, R. J. (2017). The Oral Microbiome and Adverse Pregnancy Outcomes. Int. J. Women's Health 9, 551. doi: 10.2147/IJWH.S142730

Cordioli, R. L., Kelly, P. J., Williams, K. B., Babbar, S., Angolkar, M., and Derman, R. J. (2013). Sepsis and Pregnancy: Do We Know How to Treat This Situation? Rev. Bras. Ter. Intensiva. 25 (4), 334-344. doi: 10.5935/0103-507X.20130056

Dahl, C., Stanislawski, M., Iszatt, N., Mandal, S., Lozupone, C., Clemente, J. C., et al. (2017). Gut Microbiome of Mothers Delivering Prematurely Shows Reduced Diversity and Lower Relative Abundance of Bifidobacterium and Streptococcus. PloS One 12 (10), e0184336. doi: 10.1371/journal.pone.0184336

Dahl, C., Stigum, H., Valeur, J., Iszatt, N., Lenters, V., Peddada, S., et al. (2018). Preterm Infants Have Distinct Microbiomes Not Explained by Mode of Delivery, Breastfeeding Duration or Antibiotic Exposure. Int. J. Epidemiol. 47 (5), 1658-1669. doi: 10.1093/ije/dyy064

Darkwa, E. O., Djagbletey, R., Sottie, D., Owoo, C., Vanderpuye, N. M., Essuman, R., et al. (2018). Serum Nitric Oxide Levels in Healthy Pregnant Women: A Case-Control Study in a Tertiary Facility in Ghana. Matern Health. Neonatol. Perinatol. 4 (1), 1-5. doi: 10.1186/s40748-017-0072-y

de Souza Massoni, R. S., Aranha, A. M. F., Matos, F. Z., Guedes, O. A., Borges, Á. H., Miotto, M., et al. (2019). Correlation of Periodontal and Microbiological Evaluations, With Serum Levels of Estradiol and Progesterone, During Different Trimesters of Gestation. Sci. Rep. 9 (1), 1-9. doi: 10.1038/s41598-019-48288-w

Devi, P., Nanaji, Y., Khanna, N., Yadav, A. K., and Pawar, S. V.. (2021). Animal Models for Probiotic Interventions Under Gut Inflammatory Conditions. In Kaur I. P., Pawar S. V and Rishi P. (eds) Probiotic Research in Therapeutics. Springer, Singapore 85-121. doi: 10.1007/978-981-33-6236-9_4

Dewhirst, F. E., Chen, T., Izard, J., Paster, B. J., Tanner, A. C., Yu, W.-H., et al. (2010). The Human Oral Microbiome. J. Bacteriol. 192 (19), 5002-5017. doi: $10.1128 /$ JB.00542-10 
DiGiulio, D. B., and Callahan, B. J.. (2015). Temporal and Spatial Variation of the Human Microbiota During Pregnancy. Proc. Natl. Acad. Sci. U. S. A. 112 (35), 11060-11065. doi: 10.1073/pnas.1502875112

Di Simone, N., Santamaria Ortiz, A., Specchia, M., Tersigni, C., Villa, P., Gasbarrini, A., et al. (2020). Recent Insights on the Maternal Microbiota: Impact on Pregnancy Outcomes. Front. Immunol. 11, 2372. doi: 10.3389/ fimmu.2020.528202

Edwards, S. M., Cunningham, S. A., Dunlop, A. L., and Corwin, E. J.. (2017). The Maternal Gut Microbiome During Pregnancy. MCN. Am. J. Matern Child Nurs. 42 (6), 310. doi: 10.1097/NMC.0000000000000372

Elkus, R., and Popovich, J.Jr (1992). Respiratory Physiology in Pregnancy. Clin Chest. Med. 13 (4), 555-565. doi: 10.1016/S0272-5231(21)01125-4

Farrell, J. J., Zhang, L., Zhou, H., Chia, D., Elashoff, D., Akin, D., et al. (2012). Variations of Oral Microbiota Are Associated With Pancreatic Diseases Including Pancreatic Cancer. Gut 61 (4), 582-588. doi: 10.1136/gutjnl-2011300784

Figuero, E., Han, Y. W., and Furuichi, Y. (2020). Periodontal Diseases and Adverse Pregnancy Outcomes: Mechanisms. Periodontol. 2000. 83 (1), 175-188. doi: $10.1111 /$ prd.12295

Fuhler, G. M. (2020). The Immune System and Microbiome in Pregnancy. Best Pract. Res. Clin. Gastroenterol. 44-45, 101671. doi: 10.1016/j.bpg.2020.101671

Fujiwara, N., Tsuruda, K., Iwamoto, Y., Kato, F., Odaki, T., Yamane, N., et al. (2017). Significant Increase of Oral Bacteria in the Early Pregnancy Period in Japanese Women. J. Invest. Clin. Dentist 8 (1), e12189. doi: 10.1111/jicd.12189

Furfaro, L. L., Chang, B. J., and Payne, M. S. (2018). Applications for Bacteriophage Therapy During Pregnancy and the Perinatal Period. Front. Microbiol. 8. doi: 10.3389/fmicb.2017.02660

Ghimire, K., Altmann, H. M., Straub, A. C., and Isenberg, J. S.. (2017). Nitric Oxide: What's New to NO? Am. J. Physiol. Cell Physiol. 312 (3), C254-c262. doi: 10.1152/ajpcell.00315

Gomes, C. F., Sousa, M., Lourenço, I., Martins, D., and Torres, J.. (2018). Gastrointestinal Diseases During Pregnancy: What Does the Gastroenterologist Need to Know? Ann. Gastroenterol. 31 (4), 385-394. doi: 10.20524/aog.2018.0264

Gürsoy, M., Haraldsson, G., Hyvönen, M., Sorsa, T., Pajukanta, R., and Könönen, E.. (2009). Does the Frequency of Prevotella Intermedia Increase During Pregnancy? Oral. Microbiol. Immunol. 24 (4), 299-303.doi: 10.1111/j.1399302X.2009.00509.x.

Hegewald, M. J., and Crapo, R. O. (2011). Respiratory Physiology in Pregnancy. Clinics Chest. Med. 32 (1), 1-13. doi: 10.1016/j.ccm.2010.11.001

Hendriks, E., MacNaughton, H., and MacKenzie, M. C. (2019). First Trimester Bleeding: Evaluation and Management. Am. Fam. Phys. 99 (3), 166-174.

Herrero, B. T., Martínez, M. R., Plaza, M. L., Gutiérrez, L., García, R. P., García, J. C., et al. (2001). Signos Y Síntomas Gastrointestinales Durante El Embarazo Y Puerperio En Una Muestra De Mujeres Españolas. Atencion. Primaria. 28 (1), 53-58. doi: 10.1016/S0212-6567(01)78896-8

Hezel, M., and Weitzberg, E. (2015). The Oral Microbiome and Nitric Oxide Homoeostasis. Oral. Dis. 21 (1), 7-16. doi: 10.1111/odi.12157

Hiltunen, H., Collado, M. C., Ollila, H., Kolari, T., Tölkkö, S., Isolauri, E., et al. (2021). Spontaneous Preterm Delivery Is Reflected in Both Early Neonatal and Maternal Gut Microbiota. Pediatr. Res., 1-8. doi: 10.1038/s41390-021-01663-8

Jarde, A., Lewis-Mikhael, A.-M., Moayyedi, P., Stearns, J. C., Collins, S. M., Beyene, J., et al. (2018). Pregnancy Outcomes in Women Taking Probiotics or Prebiotics: A Systematic Review and Meta-Analysis. BMC Pregnancy. Childbirth. 18 (1), 1-14. doi: 10.1186/s12884-017-1629-5

Jarvis, S., and Nelson-Piercy, C. (2020). Common Symptoms and Signs During Pregnancy. Obstet. Gynaecol. Reprod. Med. 24 (8), 245-249. doi: 10.1016/ j.ogrm.2020.07.005

Jiang, G., Zhou, Z., Li, X., Qian, Y., and Wang, K. (2021). The Gut Microbiome During Pregnancy. Matern Fetal. Med. doi: 10.1097/FM9.0000000000000091

Kattah, A., Milic, N., White, W., and Garovic, V. (2017). Spot Urine Protein Measurements in Normotensive Pregnancies, Pregnancies With Isolated Proteinuria and Preeclampsia. Am. J. Physiol. Regul. Integr. Comp. Physiol. 313 (4), R418-r424. doi: 10.1152/ajpregu.00508.2016

Kilian, M., Chapple, I., Hannig, M., Marsh, P., Meuric, V., Pedersen, A., et al. (2016). The Oral Microbiome-An Update for Oral Healthcare Professionals. Br. Dental J. 221 (10), 657-666. doi: 10.1038/sj.bdj.2016.865

Kobaly, K., and Mandel, S. J. (2019). Hyperthyroidism and Pregnancy. Endocrinol. Metab. Clinics 48 (3), 533-545. doi: 10.1016/j.ecl.2019.05.002
Koren, O., Goodrich, J. K., Cullender, T. C., Spor, A., Laitinen, K., Bäckhed, H. K., et al. (2012). Host Remodeling of the Gut Microbiome and Metabolic Changes During Pregnancy. Cell 150 (3), 470-480. doi: 10.1016/j.cell.2012.07.008

Kroon, S. J., Ravel, J., and Huston, W. M. (2018). Cervicovaginal Microbiota, Women's Health, and Reproductive Outcomes. Fertil. Steril. 110 (3), 327-336. doi: 10.1016/j.fertnstert.2018.06.036

Kumar, A., Basra, M., Begum, N., Rani, V., Prasad, S., Lamba, A. K., et al. (2013). Association of Maternal Periodontal Health With Adverse Pregnancy Outcome. J. Obstet. Gynaecol. Res. 39 (1), 40-45. doi: 10.1111/j.1447-0756.2012.01957.x

Lee, S.-Y., Chien, D.-K., Huang, C.-H., Shih, S.-C., Lee, W.-C., and Chang, W.-H.. (2017). Dyspnea in Pregnancy. Taiwanese J. Obstet. Gynecol. 56 (4), 432-436. doi: 10.1016/j.tjog.2017.04.035

Leitich, H., Bodner-Adler, B., Brunbauer, M., Kaider, A., Egarter, C., and Husslein, P.. (2003). Bacterial Vaginosis as a Risk Factor for Preterm Delivery: A MetaAnalysis. Am. J. Obstet. Gynecol. 189 (1), 139-147. doi: 10.1067/mob.2003.339

Lemos, A., de Souza, A. I., Figueiroa, J. N., Cabral-Filho, J. E., and de Andrade, A. D.. (2010). Respiratory Muscle Strength in Pregnancy. Respir. Med. 104 (11), 1638-1644. doi: 10.1016/j.rmed.2010.05.020

Li, X., Zheng, J., Ma, X., Zhang, B., Zhang, J., Wang, W., et al. (2021). The Oral Microbiome of Pregnant Women Facilitates Gestational Diabetes Discrimination. J. Genet. Genomics. 48 (1), 32-39. doi: 10.1016/j.jgg.2020.11.006

Lin, W., Jiang, W., Hu, X., Gao, L., Ai, D., Pan, H., et al. (2018). Ecological Shifts of Supragingival Microbiota in Association With Pregnancy. Front. Cell. Infect. Microbiol. 8, 24. doi: 10.3389/fcimb.2018.00024

Marangoni, A., Laghi, L., Zagonari, S., Patuelli, G., Zhu, C., Foschi, C., et al. (2021). New Insights Into Vaginal Environment During Pregnancy. Front. Mol. Biosci. 8. doi: $10.3389 /$ fmolb.2021.656844

Maresh, M. (1990). Medical Complications in Pregnancy. Baillieres Clin. Obstet. Gynaecol 4 (1), 129-147. doi: 10.1016/s0950-3552(05)80216-0

Mendling, W. (2016). Normal and Abnormal Vaginal Microbiota. LaboratoriumsMedizin 40 (4), 239-246. doi: 10.1515/labmed-2016-0011

Miller, C., McQuade, M., MacCallum, J., and Zhang, Y. V.. (2020). Persistently Elevated hCG in a Patient With No Clear Evidence of Pregnancy. Clin. Chim. Acta 510, 703-706. doi: 10.1016/j.cca.2020.09.004

Mockridge, A., and Maclennan, K. (2019). Physiology of Pregnancy. Anaesthesia. Intensive Care Med. 20 (7), 397-401. doi: 10.1016/j.mpaic.2019.05.001

Morton, A. (2020). Physiological Changes and Cardiovascular Investigations in Pregnancy. Heart Lung Circ. 30 (1), e6-e15.

Morton, A. (2021). Physiological Changes and Cardiovascular Investigations in Pregnancy. Heart Lung Circ. 30 (1), e6-e15.doi: 10.1016/j.hlc.2020.10.001

Muramatsu, Y., and Takaesu, Y. (1994). Oral Health Status Related to Subgingival Bacterial Flora and Sex Hormones in Saliva During Pregnancy. Bull. Tokyo Dental Coll. 35 (3), 139-151.

Mysorekar, I. U., and Cao, B. (2014). Microbiome in Parturition and Preterm Birth. Semin. Reprod. Med. 32 (1), 50-55. doi: 10.1055/s-0033-1361830.

Nelson, D. B., Rockwell, L. C., Prioleau, M. D., and Goetzl, L.. (2016). The Role of the Bacterial Microbiota on Reproductive and Pregnancy Health. Anaerobe 42, 67-73. doi: 10.1016/j.anaerobe.2016.09.001

Neuman, H., and Koren, O. (2017). The Pregnancy Microbiome. Nestle. Nutr. Inst. Workshop Ser. 88, 1-9. doi: 10.1159/000455207

Noyes, N., Cho, K.-C., Ravel, J., Forney, L. J., and Abdo, Z.. (2018). Associations Between Sexual Habits, Menstrual Hygiene Practices, Demographics and the Vaginal Microbiome as Revealed by Bayesian Network Analysis. PloS One 13 (1), e0191625. doi: 10.1371/journal.pone.0191625

Noyola-Martínez, N., Halhali, A., and Barrera, D. (2019). Steroid Hormones and Pregnancy. Gynecol. Endocrinol. 35 (5), 376-384. doi: 10.1080/09513590.2018.1564742

Nuriel-Ohayon, M., Neuman, H., Ziv, O., Belogolovski, A., Barsheshet, Y., Bloch, N., et al. (2019). Progesterone Increases Bifidobacterium Relative Abundance During Late Pregnancy. Cell Rep. 27 (3), 730-736.e3. doi: 10.1016/j.celrep.2019.03.075

Nuriel-Ohayon, M., Neuman, H., and Koren, O. (2016). Microbial Changes During Pregnancy, Birth, and Infancy. Front. Microbiol. 7, 1031. doi: 10.3389/fmicb.2016.01031

Oktaviyani, D., Alawiyyah, R. Z., Nusaiba, P., and Malik, A. (2021). A Review: Composition of Neonatal Meconium Microbiota and Its Role for Potential Probiotic. Pharm. Sci. Res. 8 (1), 6.

Othman, M., Alfirevic, Z., and Neilson, J. P. (2007). Probiotics for Preventing Preterm Labour. Cochrane Database Syst. Rev. (1), CD005941. doi: 10.1002/ 14651858.CD005941.pub2 
Othman, M., Alfirevic, Z., and Neilson, J. P. (2007). Probiotics for Preventing Preterm Labour. Cochrane Database Syst. Rev. 2017 (1), CD005941. doi: 10.1002/14651858.CD005941.pub2.

Park, S., Lee, S. M., Park, J. S., Hong, J.-S., Chin, H. J., Na, K. Y., et al. (2017). Midterm eGFR and Adverse Pregnancy Outcomes: The Clinical Significance of Gestational Hyperfiltration. Clin. J. Am. Soc. Nephrol. 12 (7), 1048-1056. doi: 10.2215/CJN.12101116

Parolin, C., Foschi, C., Laghi, L., Zhu, C., Banzola, N., Gaspari, V., et al. (2018). Insights Into Vaginal Bacterial Communities and Metabolic Profiles of Chlamydia Trachomatis Infection: Positioning Between Eubiosis and Dysbiosis. Front. Microbiol. 9, 600. doi: 10.3389/fmicb.2018.00600

Parry, L. J., and Vodstrcil, L. A. (2007). Relaxin Physiology in the Female Reproductive Tract During Pregnancy. Relaxin. Relat. Peptides. p, 34-48. doi: 10.1007/978-0-387-74672-2_4

Paul, H. A., Collins, K. H., Bomhof, M. R., Vogel, H. J., and Reimer, R. A. (2018). Potential Impact of Metabolic and Gut Microbial Response to Pregnancy and Lactation in Lean and Diet-Induced Obese Rats on Offspring Obesity Risk. Mol. Nutr. Food Res. 62 (4). doi: 10.1002/ mnfr.201700820

Patel, P., and Balanchivadze, N. (2021). Hematologic Findings in Pregnancy: A Guide for the Internist. Cureus 13 (5), e15149. doi: 10.7759/ cureus. 15149

Pelzer, E. S., Allan, J. A., Theodoropoulos, C., Ross, T., Beagley, K. W., and Knox, C. L.. (2012). Hormone-Dependent Bacterial Growth, Persistence and Biofilm Formation-a Pilot Study Investigating Human Follicular Fluid Collected During IVF Cycles. Plos One 7 (12), e49965. doi: 10.1371/ journal.pone.0049965

Qu, X. M., Wu, Z. F., Pang, B. X., Jin, L. Y., Qin, L. Z., and Wang, S. L.. (2016). From Nitrate to Nitric Oxide: The Role of Salivary Glands and Oral Bacteria. J. Dent. Res. 95 (13), 1452-1456. doi: 10.1177/0022034516673019

Rapone, B., Ferrara, E., Montemurro, N., Converti, I., Loverro, M., Loverro, M. T., et al. (2020). Oral Microbiome and Preterm Birth: Correlation or Coincidence? A Narrative Review. Open Access Macedonian. J. Med. Sci. 8 (F), 123-132. doi: 10.3889/oamjms.2020.4444

Saadaoui, M., Singh, P., and Al Khodor, S. (2021). Oral Microbiome and Pregnancy: A Bidirectional Relationship. J. Reprod. Immunol. p, 103293. doi: 10.1016/j.jri.2021.103293

Sanghavi, M., and Rutherford, J. D. (2014). Cardiovascular Physiology of Pregnancy. Circulation 130 (12), 1003-1008. doi: 10.1161/ CIRCULATIONAHA.114.009029

Scholl, T. O., and Reilly, T. (2000). Anemia, Iron and Pregnancy Outcome. J. Nutr. 130 (2), 443S-447S. doi: 10.1093/jn/130.2.443S

Suarez, M. L. G., Kattah, A., Grande, J. P., and Garovic, V.. (2019). Renal Disorders in Pregnancy: Core Curriculum 2019. Am. J. Kidney Dis. 73 (1), 119-130. doi: 10.1053/j.ajkd.2018.06.006
Sykes, L., and Bennett, P. R. (2018). Efficacy of Progesterone for Prevention of Preterm Birth. Best Pract. Res. Clin. Obstet. Gynaecol. 52, 126-136. doi: 10.1016/j.bpobgyn.2018.08.006

Turjeman, S., Collado, M. C., and Koren, O. (2021). The Gut Microbiome in Pregnancy and Pregnancy Complications. Curr. Opin. Endocrine. Metab. Res. 18, 133-138. doi: 10.1016/j.coemr.2021.03.004

Walker, M. Y., Pratap, S., Southerland, J. H., Farmer-Dixon, C. M., Lakshmyya, K., and Gangula, P. R.. (2018). Role of Oral and Gut Microbiome in Nitric OxideMediated Colon Motility. Nitric. Oxide 73, 81-88. doi: 10.1016/ j.niox.2017.06.003

Willmott, T., McBain, A. J., Humphreys, G. J., Myers, J., and Cottrell, E.. (2020). Does the Oral Microbiome Play a Role in Hypertensive Pregnancies? Front. Cell. Infect. Microbiol. 10. doi: 10.3389/fcimb.2020.00389

Xu, L., Huang, L., Lian, C., Xue, H., Lu, Y., Chen, X., et al. (2020). Vaginal Microbiota Diversity of Patients With Embryonic Miscarriage by Using $16 \mathrm{~s}$ rDNA High-Throughput Sequencing. Int. J. Genomics 2020. doi: 10.1155/ 2020/1764959

Yang, H., Guo, R., Li, S., Liang, F., Tian, C., Zhao, X., et al. (2020). Systematic Analysis of Gut Microbiota in Pregnant Women and its Correlations With Individual Heterogeneity. NPJ Biofilms Microbiomes 6 (1), 1-12. doi: 10.1038/ s41522-020-00142-y

Yokoyama, M., Hinode, D., Yoshioka, M., Fukui, M., Tanabe, S., Grenier, D., et al. (2008). Relationship Between Campylobacter Rectus and Periodontal Status During Pregnancy. Oral. Microbiol. Immunol. 23 (1), 55-59. doi: 10.1111/ j.1399-302X.2007.00391.x

Zullino, S., Buzzella, F., and Simoncini, T. (2018). Nitric Oxide and the Biology of Pregnancy. Vasc. Pharmacol. 110, 71-74. doi: 10.1016/j.vph.2018.07.004

Conflict of Interest: The authors declare that the research was conducted in the absence of any commercial or financial relationships that could be construed as a potential conflict of interest.

Publisher's Note: All claims expressed in this article are solely those of the authors and do not necessarily represent those of their affiliated organizations, or those of the publisher, the editors and the reviewers. Any product that may be evaluated in this article, or claim that may be made by its manufacturer, is not guaranteed or endorsed by the publisher.

Copyright (C) 2022 Zakaria, Al-Rumaihi, Al-Absi, Farah, Elamin, Nader, Bouabidi, Suleiman, Nasr and Al-Asmakh. This is an open-access article distributed under the terms of the Creative Commons Attribution License (CC BY). The use, distribution or reproduction in other forums is permitted, provided the original author(s) and the copyright owner(s) are credited and that the original publication in this journal is cited, in accordance with accepted academic practice. No use, distribution or reproduction is permitted which does not comply with these terms. 